\title{
VALORACIÓN INDIVIDUAL DE RIESGO DE CARIES CON EL RIESGOGRAMA*
}

\author{
${ }^{1}$ Marisol Téllez M., ${ }^{2}$ Stefanía Martignon B., ${ }^{3}$ Andrea del Pilar Cortés P., ${ }^{4}$ Héctor Fernando Gómez G. \\ ${ }^{1}$ Odontóloga U. El Bosque, PhD en Epidemiología University of Michigan, Profesor Asociado Unidad de Investigación en Caries UNICA. \\ F. de Odontología U. El Bosque. ${ }^{2}$ Odontóloga U. Javeriana, Especialista en Odontología Pediátrica U. El Bosque, PhD en Caries \\ University of Copenhagen, Profesor Asociado Unidad de Investigación en Caries UNICA F. de Odontología U. El Bosque. \\ ${ }^{3}$ Odontológa Universidad El Bosque, Asistente de Investigación Unidad de Investigación en Caries, F. de Odontología U. El Bosque. \\ ${ }^{4}$ Odontólogo U. El Bosque.
}

\section{Autor responsable de correspondencia: Marisol Téllez $M$.}

Correoelectrónico:mtellez@umich.edu

\section{RESUMEN}

Objetivo: Establecer el riesgo de caries dental con el "RIESGOGRAMA" en población colombiana y evaluar diferencias existentes entre departamentos.

Materiales y métodos: Se desarrolló una adaptación local del software CARIOGRAM ${ }^{\circledR}$, de acuerdo a la morbilidad oral por caries dental en el país. Se evaluaron múltiples factores de riesgo en siete departamentos del país: experiencia de caries, presencia de placa, retención de placa sistémica o local, uso de pasta dental con flúor, frecuencia de ingesta diaria y número de veces de consumo de comidas altas en carbohidratos, y motivo para la última consulta odontológica. Se realizó un análisis descriptivo de la información utilizando SAS 9.1. Se determinó la sensibilidad y especificidad del nuevo instrumento usando como comparación el CRT Buffer y CRT Bacteria Vivadent ${ }^{\circledR}$. Resultados: Se recolectaron 4,942 formatos de siete departamentos. Alrededor del 62\% de la muestra presentó un COP-D >1 y aquellos departamentos de mayor extensión presentaron la menor proporción de población con COP-D $=0$. El $82 \%$ reportó el uso de crema dental con flúor y el 61\% reportó haber tenido acceso al odontólogo por un motivo diferente a urgencia. El 11\% de la población estudiada fue clasificada en riesgo alto de caries, mientras el 25\% fue clasificado en riesgo medio. La sensibilidad del Riesgograma fue del $75 \%$. Conclusión: La valoración individual de riesgo de caries es un indicador importante de salud oral y debe ser evaluado de manera integral con el fin de determinar el riesgo que tiene individualmente cada paciente de desarrollar nuevas lesiones de caries. [Téllez M, Martignon S, Cortés A, Gómez H. Valoración individual de riesgo de caries con el riesgograma. Ustasalud 2009; 8: 69 - 74]

Palabras clave: Caries dental, Riesgo, Cariogram, Placa dental.

\section{INDIVIDUAL CARIES RISK ASSESSMENT USING “RIESGOGRAMA"}

\begin{abstract}
Objective: To establish caries risk through "RIESGOGRAMA" among Colombians and evaluate existing differences between states. Methods: A local adaptation of the CARIOGRAM ${ }^{\circledR}$ software was developed considering caries morbidity in Colombia. Using Riesgograma, multiple risk factors were evaluated in 7 states in the country (caries experience, dental plaque, local systemic factors for plaque retention, flúoride access, daily frequency of intake and timing and reason for last dental visit). Frequency distributions and means were generated using SAS 9.1. Sensitivity and specificity were measured using as comparison CRT Buffer and CRT Bacteria Vivadent ${ }^{\circledR}$. Results: A total of 4,942 forms were collected in 7 states of the country. Regarding dental caries, around $62 \%$ of the sample had a DMF$\mathrm{T}>1$, and the largest states had the lowest proportion of population with a DMT-T $=0$. Almost $82 \%$ reported using toothpaste with fluoride, while $61 \%$ reported having no access to dental services non-emergency related. When caries risk was assessed $11 \%$ of the population was classified as high risk, and $25 \%$ fell into the medium risk group. Sensitivity of Riesgograma was $75 \%$.

Conclusion: Caries individual risk assessment is an important health indicator and it must be evaluated in a comprehensive way to asses the risk that each person has to develop new caries lesions.
\end{abstract}

Key words: Dental caries, Risk, Cariogram, Dental plaque.

Recibido para publicación: 21 de agosto de 2009. Aceptado para publicación: 30 de noviembre de 2009.

* Unidad de Investigación en Caries UNICA. 


\section{INTRODUCCIÓN}

La caries dental se define como una patología bacteriana que tiene como resultado la destrucción de la estructura dental causada por el ácido formado por las bacterias que están presentes en la placa dental. El ácido produce una disolución de los minerales en la superficie dental. De allí, la importancia de contar con concentraciones mínimas de flúor en boca para mitigar los efectos del proceso de desmineralización.

Existen otros factores de riesgo que junto con la presencia de los ácidos bacterianos, hacen que la probabilidad de desarrollar lesiones de caries se vea aumentada. Dentro de estos otros factores se encuentran: la frecuente ingesta de carbohidratos y los bajos niveles de flujo salivar entre otros. ${ }^{1}$ Los carbohidratos sirven como fuente nutricional de las bacterias productoras de ácidos y junto con un flujo salivar reducido, o un $\mathrm{pH}$ salivar muy ácido, las probabilidades de que se genere un medio para el desarrollo de bacterias cariogénicas y de pérdida de minerales son muy altas. Sin embargo, el nivel de pH típico de la saliva y la concentración suficiente de iones de flúor sirven para que exista una menor agregación de la placa bacteriana a la superficie dental. ${ }^{1}$

Entre los predictores de riesgo de caries más importantes reportados en la literatura se encuentra la experiencia de caries dental registrada como COP dental. ${ }^{2,3}$ Este registro considera el número de dientes con caries cavitacional, dientes obturados y dientes perdidos por caries. Adicionalmente, otros predictores de riesgo que contribuyen al desarrollo de nuevas lesiones son: la higiene oral que determina la concentración de bacterias en la cavidad oral y la presencia de microorganismos cariogénicos en la placa, la saliva, la historia acerca del uso de flúor y los factores socioeconómicos los cuales pueden llegar a influir en el auto cuidado del paciente., ${ }^{2,6}$

En Colombia, se observa todavía una experiencia de caries bastante elevada tanto en la población infantil como en la población adulta con un aumento en el valor del COP dental en la medida en que avanza la edad. ${ }^{5}$ En relación con la presencia de placa en la población colombiana, el $60 \%$ de la población tiene una buena higiene oral según el último Estudio Nacional de Salud Bucal, aunque este fenómeno puede estar asociado a la pérdida de superficies dentarias que se examinan y que aumentan proporcionalmente con la edad. ${ }^{5}$ Además, el modelo de consulta odontológica que prima en el país, se debe en una alta proporción a urgencias odontológicas y no a razones de tipo preventivo. ${ }^{5}$

La ausencia de una valoración de riesgo de caries que permita determinar los factores asociados a esta condición y predecir qué pacientes son más o menos propensos a desarrollar la patología es una constante tanto en los servicios odontológicos privados como en los públicos. La ausencia de pruebas de tamizaje rápidas que se puedan aplicar a nivel poblacional, así como los altos costos asociados a las pruebas microbiológicas y salivares disponibles en la actualidad, hacen que sea un tema prioritario dentro de la salud pública odontológica. La clasificación de los pacientes en grupos según el riesgo alto, medio o bajo, después de realizar una valoración individual, permite mejorar los planes de tratamiento en el largo plazo y hacerlos más costo-efectivos.?

Dentro de las herramientas con las que se cuenta en la actualidad para valorar el riesgo de caries, está el CARIOGRAM $^{\circledR 8}{ }^{8}$ Este software expresa, las posibles interacciones entre los diferentes factores de riesgo introducidos de forma individual que influyen en la enfermedad de caries (contenido y frecuencia de la dieta, tipo y cantidad de placa, utilización de fluoruros y secreción salivar, entre otros) agrupados en cuatro grandes bloques causales porcentuales (dieta, bacterias, susceptibilidad y circunstancias) que valoran el riesgo de caries enfrentados a un quinto sector que estima la oportunidad real para evitar una nueva lesión de caries dental.

En nuestro medio, el acceso a este tipo de software se ve limitado en múltiples ocasiones debido a restricciones de tipo económico en los programas de salud, tiempo o protocolos de manejo ya establecidos por las instituciones en donde no hay cabida para instrumentos adicionales y menos si éstos deben ser manejados a través de un computador. Para que un instrumento de tamizaje tenga un impacto importante a nivel social debe ser de fácil acceso, sencillo de usar, no requerir mayores elementos tecnológicos $\mathrm{y}$, sobre todo, tener un buen poder predictivo. Son estos motivos los que llevaron al diseño del "Riesgograma", una versión modificada del programa "CARIOGRAM" que tiene como propósito fomentar la valoración de riesgo de caries y la introducción de medidas preventivas antes de que se puedan desarrollar nuevas lesiones. Esta herramienta estima el riesgo de caries a través del análisis de factores interactuando directamente en el proceso de caries sobre la superficie dental. Evalúa siete factores de riesgo individuales con puntajes de $0-20$, los cuales están divididos en cuatro sectores: rojo -experiencia de caries, -placa bacteriana, -factores locales/sistémicos de retención de placa, azul -contenido de la dieta, -frecuencia de ingestas diarias y, -momento, verde -uso de flúor y morado -acceso y motivo de última consulta odontológica; el resultado de la suma de puntajes corresponde a un valor entre 0 y 100 , lo cual estima un riesgo bajo 
(0-40), mediano (50-60) o alto (70-100). Este instrumento no requiere el uso de un equipo en especial y su diligenciamiento se realiza en un formato que arroja un valor predictivo a la sumatoria de todas sus variables (Riesgo Total). ${ }^{8}$ El objetivo del estudio fue establecer el riesgo de caries dental con el "RIESGOGRAMA" en población colombiana y evaluar diferencias existentes entre departamentos.

\section{MATERIALES Y MÉTODOS}

En octubre de 2006 se llevó a cabo un entrenamiento de valoración de riesgo de caries dental dirigido a aproximadamente 500 odontólogos durante al Mes de la Salud Oral organizado por Colgate Palmolive, en la ciudad de Bogotá. Los asistentes provenientes de varios departamentos del país, fueron dotados con kits que contenían información correspondiente al Riesgograma para ser usado en sus pacientes. A este grupo de odontólogos, se les solicitó enviar de manera voluntaria los formatos completos a la Universidad El Bosque, para el respectivo procesamiento de la información. El Riesgograma es una adaptación local del software CARIOGRAM que tiene en cuenta los datos de COP-D según los diferentes grupos etáreos reportados en el ENSAB III. ${ }^{5} \mathrm{El}$ Riesgograma evalúa múltiples factores de riesgo tales como: experiencia de caries (COP-D, ceo-d, ceo-d + COP-D que junto con la edad son analizados para establecer puntajes de 0,10 y 20) presencia de placa según criterios del Índice de Sillness y Löe (placa gruesa presente $=1$, placa gruesa ausente $=0$ según la sumatoria de 4 dientes índices sugeridos), retención de placa sistémica o local (no retención $=0$, retención $=10$ ), uso de crema dental con flúor (uso mínimo 2 veces al día $=0$, menos de 2 veces/día $=10$, no uso $=20$ ), frecuencia de ingesta diaria (máximo 7 comidas al día incluidos bebidas y pasabocas $=0,>$ 7 veces/día $=20$ ), número de veces de consumo de comidas altas en carbohidratos (máximo 1 porción/ semana $=0,>1$ porción $/$ semana $=20$ ), y motivo para la última consulta odontológica (acceso adecuado (cita hace menos de 1 año por razones preventivas) $=0$, acceso inadecuado (cita hace más de 1 año por urgencia) $=20$ ).

Un total de 4942 formatos de Riesgograma fueron diligenciados y enviados a la Universidad El Bosque de manera voluntaria para su respectivo análisis en el año 2007. Aproximadamente, el $4 \%$ de los formatos recibidos presentaban datos ausentes en múltiples variables ( $=>3$ variables), suma de valores inconsistente, y selección de más de una respuesta en casillas donde sólo se permitía una opción, entre otros, por lo cual fueron excluidos. Únicamente fueron incluidos aquellos formatos diligenciados por odontólogos entrenados en el Mes de la Salud Oral y donde no se hubiera perdido más del $30 \%$ de la información solicitada. Los formatos enviados para procesamiento no contenían datos de identificación de los pacientes evaluados por lo cual se asignaron números de identificación únicos, que permitieron garantizar la confidencialidad de los odontólogos que enviaron la información de manera voluntaria a la Universidad.

Se realizó un estudio de corte transversal, con un análisis descriptivo (tablas de frecuencia y promedios) según la naturaleza de las variables. La prevalencia de los diferentes factores de riesgo y la suma total del riesgo de caries dental fueron estratificados por la variable de departamento para evaluar si existían diferencias geográficas. La información fue analizada mediante el paquete estadístico SAS versión 9.1.

Para determinar la sensibilidad y la especificidad del Riesgograma, se evaluó un grupo de 20 pacientes externos al estudio en mención, a los cuales se les realizó valoración de riesgo mediante una prueba salivar de Vivadent ${ }^{\circledR}$ CRT Buffer y CRT Bacteria y simultáneamente mediante la aplicación del instrumento desarrollado (Riesgograma).

\section{RESULTADOS}

En dentición permanente, se encontró una alta experiencia de caries en general en todos los departamentos. El 62\% ( $n=2924)$ de la muestra estudiada presentó dientes cariados, obturados o perdidos por caries. El departamento que presentó la mayor experiencia de caries fue Magdalena con una prevalencia de $95 \%(n=19)$, seguido de Valle $84 \%$ $(n=448)$. Por otra parte, el departamento que presentó la mayor proporción de COP-D $=0$ fue Quindío con un $66 \%(n=822)$ (Figura 1$)$.

La valoración de presencia de placa mediante el Índice Modificado de Sillness y Löe, arrojó que el 31\% $(n=1759)$ de la población estudiada presentó placa al momento de la consulta. La mayor proporción de población con presencia de placa correspondió al departamento de Quindío con un 54\% ( $\mathrm{n}=980$ ), seguido de Santander con un $42 \%(n=8)$. En el departamento del Magdalena ninguno de los individuos evaluados $(n=20)$ presentó placa en el momento de la consulta (Figura 2).

$\mathrm{Al}$ estudiar el índice de placa es importante determinar si existen o no factores de retención. Únicamente, el $3 \%(n=167)$ de la muestra presentó factores de retención sistémica tales como: hiposalivación. Mientras que el 23\% ( $n=1058)$ presentó factores de retención local, entre los que se encontraban: aparatología fija como ortodoncia, prótesis fijas desadaptadas, restauraciones desadaptadas, aparatos ortopédicos, retenedores; apiñamiento dental, espacios 
desdentados, hipoplasias, surcos y fosas profundas. Se observó que el departamento que presentó el mayor porcentaje de retención de placa sistémica fue Valle con un $7 \%(n=38)$, mientras que Santander fue el departamento que presentó el mayor porcentaje de retención de placa localizada $47 \%(n=9)$.

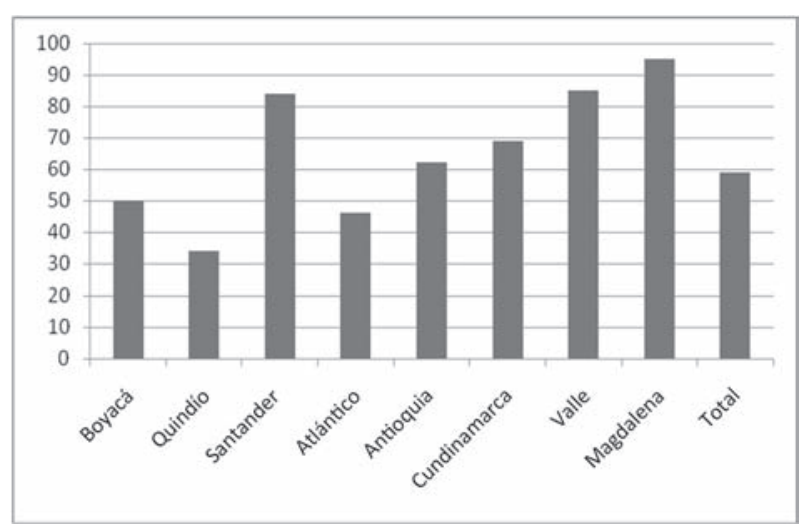

Figura 1. Experiencia de caries por departamentos (COP-D mayor a 1).

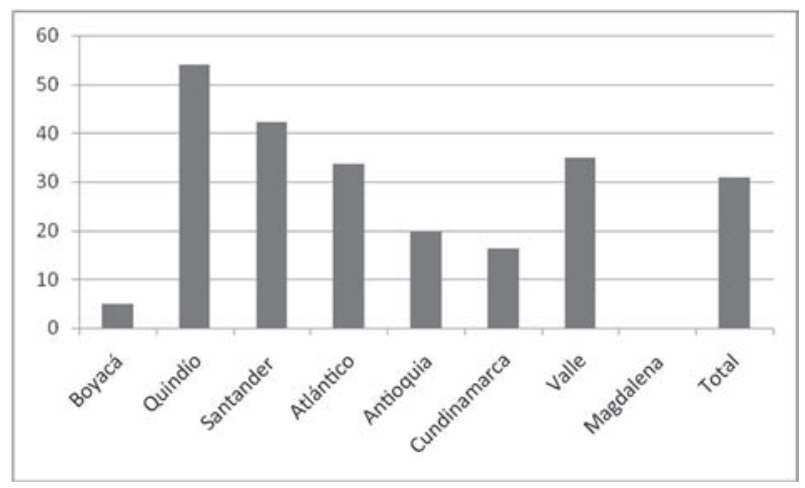

Figura 2. Porcentaje de sujetos con presencia de placa bacteriana durante el examen.
Al valorar el número de comidas, pasabocas y/o bebidas al día, se encontró que el $69 \%(n=3306)$ consume más de 7 comidas/pasabocas y/o bebidas en el día. Quindío fue el departamento que presentó el mayor consumo de porciones de carbohidratos en la semana con un $40 \%(n=740)$ y el de mayor número de comidas, pasabocas y/o bebidas al día fue Boyacá, pues un $100 \%(n=20)$ de la población estudiada en este departamento, consume más de 7 comidas diariamente. En Antioquia, se observó el menor consumo de porciones de carbohidratos en la semana (3\%) $(\mathrm{n}=26)$ y un número de comidas, pasabocas y/o bebidas menor a 7 porciones al día $37 \%(n=315)$.

Con respecto al uso de crema dental con flúor, se observó que el $82 \%(n=3826)$ de la población usa a diario crema dental con flúor al menos dos veces al día. Los departamentos que presentan el menor uso de crema dental con flúor menos de 2 veces al día son Magdalena con un $40 \%(n=8)$ seguido de Atlántico con un $48 \%(n=48)$. En los otros departamentos estudiados se observó un uso mayor al 65\% (Tabla 1).

Finalmente, los datos relacionados con acceso a consulta demostraron que el $61 \%(n=2940)$ de la población estudiada asistió a consulta odontológica en el último año por motivo diferente a urgencias. Igualmente, existen variaciones entre departamentos. Por ejemplo, Quindío mostró un porcentaje de población que accedió a consulta por motivo diferente a urgencia de $70 \%(n=1279)$, seguido de Valle y Santander con un $63 \%(n=344$ y $n=12$, respectivamente). El departamento de Atlántico mostró tener el porcentaje más bajo de población con acceso a consulta por motivo diferente a urgencia en el último año (Tabla 2).

Tabla 1. Porcentajes de uso diario de crema dental con flúor según departamento $(n=4735)$

\begin{tabular}{lccccccccc}
\hline & Total & Boyacá & Quindío & Santander & Atlántico & Antioquia & Cundinamarca & Valle & Magdalena \\
\hline $\begin{array}{l}\text { Dos } \\
\text { veces/día }\end{array}$ & 82 & 83,3 & 88,7 & 94,7 & 48,5 & 88,5 & 66,9 & 98 & 40 \\
$\begin{array}{l}\text { Una vez/ } \\
\text { día No } \\
\text { usa }\end{array}$ & 18 & 16,7 & 11,3 & 5,3 & 51,5 & 11,5 & 33,1 & 2 & 60 \\
\hline
\end{tabular}

Tabla 2. Porcentajes de acceso a consulta en el último año por motivo diferente a urgencia según departamento $(\mathrm{n}=4819)$.

\begin{tabular}{cccccccccc}
\hline & Total & Boyacá & Quindío & Santander & Atlántico & Antioquia & Cundinamarca & Valle & Magdalena \\
\hline Si & 61,2 & 40 & 70,4 & 63,2 & 35,1 & 55 & 54,1 & 63,5 & 60 \\
No & 38,7 & 60 & 29,6 & 36,8 & 64,9 & 45 & 45,9 & 36,5 & 40 \\
\hline
\end{tabular}




\section{Diferencias en clasificación de riesgo según los departamentos}

Después de valorar siete factores de riesgo y asignar un puntaje a cada uno para obtener la suma total que indica el puntaje de riesgo total, se obtuvieron puntajes en un rango de $0-100 \%$ donde: riesgo bajo (0-40\%), mediano (50-60\%) o alto (70-100\%). De los 4942 formatos, el $65 \%$ se encontraba en riesgo bajo, el $24 \%$ en riesgo medio, y el $11 \%$ se encontraba en riesgo alto.

En cuanto a la comparación de riesgo individual entre departamentos del país se observó que el único departamento que se encontró en riesgo alto fue Magdalena con $61 \%(n=12)$ mientras que la gran mayoría se ubicaron en el grupo de riesgo medio: Boyacá con $53 \%(n=11)$, Atlántico con $47 \%(n=44)$, Antioquia y Cundinamarca $(46 \%)(n=374$ y $n=623$, respectivamente). En el grupo de riesgo bajo se ubicaron Quindío con un $24 \%(n=394)$, Santander con $39 \%(n=7)$ y Valle $36 \%(n=186)$.

\section{Valoración de Sensibilidad y Especificidad}

En un grupo de 20 sujetos externos al estudio en mención, se realizó valoración de riesgo de caries dental mediante una prueba salivar de Vivadent ${ }^{\circledR}$ CRT Buffer y CRT Bacteria y simultáneamente mediante la aplicación del Riesgograma. Los datos fueron agrupados en riesgo Bajo vs. Alto, lo que permitió la construcción de tablas de $2 \times 2$ para poder determinar las características operativas de este nuevo instrumento, al tomar como patrón de oro el resultado dado por la prueba microbiológica y salivar.

Se determinó que la sensibilidad del Riesgograma fue del $75 \%$. Es decir, el Riesgograma permitió detectar en un $75 \%$, individuos que presentaban riesgo de caries dado que el individuo efectivamente presentaba un riesgo aumentado. Por otra parte, la especificidad fue del $44 \%$.

\section{DISCUSIÓN}

Se observaron varias similitudes al comparar los resultados encontrados con el ENSAB III, ${ }^{5}$ en cuanto a experiencia de caries y uso de crema dental con flúor. El $62,2 \%$ de la población tuvo un COP $>$ a 1 , mientras que en el ENSAB III la proporción de población con dientes cariados obturados y/o perdidos fue ligeramente mayor (88.8\%). Por otra parte, el porcentaje de población que presentó placa en el momento del examen fue de $32 \%$ vs. $46 \%$ del Estudio Nacional de Salud Bucal. Igualmente, el porcentaje de individuos que usaban crema dental con flúor fue superior al $80 \%$ en ambos estudios (ENSAB III $98.4 \%$ vs. Riesgograma $82 \%$ ). Estos datos reflejan la falta de cambio positivo en cuanto a morbilidad oral por caries den- tal y factores de riesgo asociados desde la conducción del ENSAB III, ${ }^{5}$ hace aproximadamente 10 años. De ahí la importancia de evaluar el impacto de los planes preventivos y de promoción a nivel nacional que se han ejecutado en la última década y que se tienen planeados para el futuro.

El alto porcentaje de presencia de placa bacteriana en el total de la muestra (37\%), y en especial en departamentos como Quindío y Santander hacen indispensable la conducción de mejores estrategias de educación en salud oral enfocadas a la remoción de este factor etiológico para caries. Mediante el uso del Riesgograma, tanto en la práctica privada como a nivel de salud pública, el odontólogo puede programar e implementar estrategias adecuadas para controlar los factores de riesgo que presenta cada paciente. Resaltar la importancia de la instrucción en higiene oral individualizada, evitar el desarrollo de lesiones de caries futuras, y modificar principalmente las variables biológicas y de comportamiento que se encuentran alteradas.

La caries dental tiene una etiología multifactorial, en donde hay una interrelación entre tres factores principalmente: el huésped (saliva y dientes), la microflora (placa), y el sustrato (dieta), y un cuarto factor: el tiempo. No existe una prueba única que tome en consideración todos estos factores y que pueda predecir de manera acertada la susceptibilidad individual para desarrollar lesiones de caries. Sin embargo, el riesgo de caries puede ser evaluado mediante el análisis integral de varios factores causales. ${ }^{9}$ En las últimas décadas, se ha observado un progreso importante en la prevención de la caries dental. Sin embargo, el riesgo de caries no permanece constante a través de la vida y puede ser modificado por intervenciones preventivas por parte del odontólogo y del paciente. ${ }^{10}$ Las lesiones iniciales de caries son supuestamente mejores predictores que el número de dientes obturados o perdidos. En los adultos, los valores de COP dental son menos sensibles para predecir caries coronal futura que en los niños. Sin embargo, parece haber una conexión entre las lesiones de caries presente y el riesgo de desarrollar caries radicular. ${ }^{11}$ La caries en dentición primaria puede predecir de una manera acertada la caries futura en dentición permanente. Aunque, la sensibilidad aumenta cuando aparte de la dentición primaria, los primeros molares permanentes son incluidos para el análisis de riesgo. ${ }^{12}$

La validez de la valoración de riesgo puede ser evaluada según características de sensibilidad, especificidad y valores predictivos negativos y positivos. Se han desarrollado múltiples modelos de regresión en donde se contemplan hasta más de 15 factores de riesgo de caries dental y donde se han obtenido ran- 
gos de sensibilidad variables, desde $59 \%$ hasta $80 \%$ y valores de especificidad alrededor del $80 \%{ }^{13,14}$ La utilización de este instrumento de tamizaje fue aceptable, si se tiene en cuenta que es de fácil manejo, económico y los resultados de sensibilidad fueron similares a los reportados en la literatura científica. Al ser comparado con otros sistemas de valoración de riesgo de caries que requieren de pruebas adicionales salivares y microbiológicas, el Riesgograma podría llegar a ser una herramienta de amplia utilidad no sólo en la clínica sino en escenarios de salud pública donde se requiera determinar de manera rápida el nivel de riesgo individual de caries dental.

Hoy en día, la disminución de la caries dental que muestra una distribución lejos de ser normal, requiere de estrategias diferentes de prevención y tratamiento. ${ }^{15}$ La tasa de progresión de caries es más lenta para aquellos individuos que usan flúor de una manera regular en comparación con aquellos que no usan o lo usan de manera inapropiada. Los tratamientos actuales de caries tales como los agentes terapéuticos antibacterianos, las aplicaciones de flúor en sus diferentes vehículos y los sellantes entre otros, deben aplicarse de manera selectiva en la población, de acuerdo con las necesidades individuales del paciente. De lo contrario, la prevención en caries no será costo-efectiva. ${ }^{15}$

Las inferencias realizadas a partir de este estudio deben ser interpretadas de manera cuidadosa pues existen limitaciones metodológicas inherentes al tipo de estudio conducido. Por haber realizado un entrenamiento en valoración de riesgo masivo (aproximadamente 500 odontólogos), la estandarización de procedimientos como la evaluación de presencia de placa bacteriana no fue posible por lo cual no se reportan mediciones de reproducibilidad y es de esperar que con un número tan alto de examinadores, los resultados referentes a placa puedan presentar una alta variación inter-examinador. Igualmente, al no haber utilizado un muestreo de tipo probabilístico y, a pesar del tamaño de muestra analizado, los resultados podrían llegar a no ser extrapolables a todos los individuos de las sub-regiones y de todos los estratos. La posibilidad de sesgos de selección existe dado que se desconoce si el grupo de odontólogos entrenados provenían del sector público o privado y el perfil socio-demográfico de los pacientes que atendían en consulta en cada una de las ciudades.

\section{CONCLUSIONES}

La valoración individual de riesgo de caries dental es un indicador importante de salud oral, que es bueno que sea evaluado de manera integral con el fin de determinar el riesgo que tiene individualmente cada paciente de presentar o de desarrollar lesiones. A pesar de que el $36 \%$ de la población estudiada, se encontró con niveles de riesgo para caries de altos a medianos, se observó una alta proporción en el uso de crema dental fluorada y un cambio de actitud en cuanto a acceso a odontología por razones de tipo preventivo y no de urgencias. Esto favorece los perfiles de morbilidad y el cambio de actitud en cuanto a la concepción de prevención, y la importancia del auto-cuidado oral a través de una visita oportuna al odontólogo.

\section{Agradecimientos}

Este estudio fue desarrollado con el apoyo de la Compañía Colgate Palmolive Colombia y el Grupo de Semilleros de la Facultad de Odontología de la Universidad El Bosque.

\section{BIBLIOGRAFÍA}

1. Kornman KS. Diagnostic and prognostic tests for oral diseases: practical applications. J Dent Educ 2005; 69: 498 - 508.

2. Halbrook WP, de Soet JJ, de Graaff J. Prediction of dental caries in pre-school children. Caries Res 1993; 27: 424- 430

3. Petersen PE, Bourgeois D, Ogawa $\mathrm{H}$, et al. The Global Burden of Oral Disease and Risk to Oral Health. Bulletin of the World Health Organization. September 2005, 83 (9).

4. Nishikawara F, Katsumura S, Ando A, Tamaki Y, Nakamura Y, Sato $\mathrm{K}$ et al. Correlation of cariogenic bacteria and dental caries in adults. N J Oral Sci 2006; 48: 245 - 251.

5. Ministerio de Salud. República de Colombia, Centro Nacional de Consultoría CNC. Estudio Nacional de Salud Bucal (ENSABIII) Tomo VII. Bogotá, Colombia. 1999.

6. Johnson MF. The role of the risk factors in the identification of appropriate subjects of caries clinical trials: design considerations. J Dent Res 2004; 83:116-118.

7. Douglass CW. Risk assessment in dentistry. J Dent Educ 1998; 62: $756-761$.

8. Bratthall D, Hänsel Petersson G, Stjernswärd JR. Cariogram, Internet Versión [en línea] 2.01., 2004. URL disponible en: http://www.scudent.com/science/operative/cariogmanual201net.pdf

9. Reich E, Lussi A, Newbrun E. Caries-risk assessment. Int Dent J 1999; 49:15 - 26

10. Axelsson P, Lindhe J, Nyström B. On the prevention of caries and periodontal disease. Results of a 15-year-longitudinal study in adults. J Clin Periodontol 1991; 18: 182 -189

11. Locker D, Slade GD, Leake JL. Prevalence of and factors associated with root decay in older adults in Canada. J Dent Res 1989; 68: $768-772$

12. Seppä L, Hausen H, Pöllänen L, Helasharju K, Kärkkäinen S. Past caries recording made in public dental clinics as predictors of caries experience in early adolescence. Community Dent Oral Epidemiol 1989; 17: 277 - 281.

13. Scheinin A, Pienihäkkinen K, Tiekso J, Holmberg S. Multifactorial modeling for root caries prediction. Community Dent Oral Epidemiol 1992; 20: 35 - 37.

14. Disney JA, Graves RC, Stamm JW, Bohannan HM, Abernathy JR, Zack DD. The University of North Carolina Caries Risk Assessment Study: further developments in caries risk prediction. Community Dent Oral Epidemiol 1992; 20: 64 - 75

15. Burt B, Eklund S. Dentistry, Dental Practice and the Community. 5th Edition. Philadelphia. Ed: W.B. Saunders Company; 1999. 